\title{
Designing an Assessment for Introductory Programming Concepts in Middle School Computer Science
}

\author{
Shuchi Grover \\ Looking Glass Ventures/Stanford University \\ Palo Alto, CA \\ shuchig@cs.stanford.edu
}

\begin{abstract}
Teaching of computer science (CS is rapidly expanding in schools. Learning to program is a key ingredient of school CS curricula, and consequently, there is a need for quality measures of student learning of foundational programming concepts. However, highquality tools for measuring student learning in introductory CS have been under-developed and under-researched. This experience report shares the process of design and refinement of a summative paperbased assessment (that could also be administered online) for introductory programming in middle grades (6-8). We share our experiences with the use of assessment as a pre-post measure in a middle school introductory programming course in diverse, urban school classrooms in the US and use that data to conduct validity, reliability and item discrimination analyses.
\end{abstract}

\section{ACM Reference format:}

Grover, S. 2020. Designing an Assessment for Introductory Programming Concepts in Middle School Computer Science. In Proceedings of 51st ACM Technical Symposium on Computer Science Education (SIGCSE'20), March 11--14, 2020, Portland, OR, USA. ACM, New York, NY, USA, 7 pages. https://doi.org/10.1145/3328778.3366896

\section{Introduction}

In recognition of our fast-changing world that is driven by computing, efforts to introduce Computer science (CS) as a new STEM discipline to all students in K-12 is rapidly gaining momentum, both nationally and globally. Programming is seen not only as a key part of all introductory computer science learning, but as a crucial $21^{\text {st }}$ century skill that can motivate and empower young learners to be creative and digitally fluent, as well as enrich learning in all subjects. Introductory programming experiences aim to provide learners with engaging early experiences to help them develop an understanding of foundational computing concepts such as loops, conditionals, variables, expressions, in addition to providing an exposure to easy-to-use engaging programming experiences to help spark young learners' interest in computing [2]. Without valid measurements, however, it is difficult to know whether students are indeed developing an understanding of key concepts. Development of high-quality assessments has sadly not

Permission to make digital or hard copies of all or part of this work for personal or classroom use is granted without fee provided that copies are not made or distributed for profit or commercial advantage and that copies bear this notice and the full citation on the first page. Copyrights for components of this work owned by others than the author(s) must be honored. Abstracting with credit is permitted. To copy otherwise, or republish, to post on servers or to redistribute to lists, requires prior specific permission and/or a fee. Request permissions from Permissions@acm.org.

SIGCSE '20, March 11-14, 2020, Portland, OR, USA

(c) 2020 Copyright is held by the owner/author(s). Publication rights licensed to ACM ACM 978-1-4503-6793-6/20/03..\$15.00

https://doi.org/10.1145/3328778.3366896 kept pace with the spread of CS programs and curricula [40] and is often called out as one of the key R\&D imperatives for computing education $[6,12,41]$. With growing availability of CS assessments at the high school level, the need for robust measurement-for both formative and summative purposes-is now acutely felt at the middle and primary school levels [7]. Additionally, although the goal of designed assessments is always to measure student learning, it need not be done with the sole aim of grading students [15]. In these nascent years of teaching CS in formal classroom settings, aggregated data from even summative assessments can be very useful to evaluate curricula, pedagogy, and progress of student learning in the K-12 years and to prompt curricular revisions.

This experience report describes the design and use of a summative instrument ('VELA Assessment') for measuring learning of introductory programming concepts in grades 6-8. With the goal of designing for future repurposing of this, e.g., designing items in different languages, we used a principled assessment design methodology - Evidence-Centered Design (ECD) [25] to (a) create assessment design patterns $[3,16]$ that can be used by others to design items and (b) focus on measuring understanding of variables, expressions, loops, conditionals, and abstraction - concepts that are foundational to most introductory programming (regardless of language), even though we designed items involving Scratch code (that could involve other concepts such as events \& broadcasts). This makes this work more generalizable than prior assessments that have focused on programming constructs in a specific programming language (e.g. [42]). After iterative rounds of piloting and refinement, the assessment was used as a pre-post measure in a middle school introductory CS class in an urban school district in USA. Classroom data were used to examine difficulty, validity and reliability After a review of relevant work, we briefly describe our design process guided by the framework [25]. We share examples of items and item refinement before describing the results of the using VELA assessment as a pre-post measure in a middle school introductory programming intervention. The paper describes validity and reliability analyses conducted on data gathered from the classroom use data, as well as student performance at various grade levels $(6,7, \& 8)$. Our findings suggest that this is a good instrument that, with accompanying rubrics and assessment design patterns, can serve as an important resource and tool for middle school CS teachers and researchers since the assessment design patterns and items can be used as a template to design assessments for imperative, procedural languages. The paper concludes with learnings and further guidance on the use of this assessment.

\section{Related Work}

This work draws on prior efforts on designing assessments for the middle school level that use multiple-choice or short-response items types (often with code snippets) and involve code-comprehension, 
debugging, writing pseudocode and evaluating code [e.g. 13,30,42]. However, those either focus heavily on programming language constructs [42] or are designed for formative use [13,30]. There is also either no data around their use or context of use [27] or missing evidence on validity and reliability of those assessments. Additionally, some recent efforts have focused on languageagnostic assessment of computational thinking [e.g. 10, 39], whereas our focus is on measuring understanding of programming concepts in the vein of a concept inventory [33] or Tew \& Guzdial's FCS1 assessment [35]. We are guided by the ECD design process and patterns [3] as well as the assessment created and attendant validity and reliability tests conducted in past research [32], for the high school Exploring Computer Science (ECS) curriculum [11].

We acknowledge that coding tasks and process-based measures are arguably more authentic, but they are challenging as assessment instruments [18]-scoring programming projects is subjective and time-consuming; and the mere presence of constructs in programs is not always an indication of understanding [17]. Additionally, past research has documented the benefits of well-designed multiplechoice items to target deeper understanding of programming concepts $[15,20,28,31,40]$. Lastly, we believe an assessment such as this one must be combined with other measures that together comprise "systems of assessments" [15]. to provide a holistic view of student understanding. This combination of measures must include programming tasks (open-ended/free-choice and closed), among other measures and tasks (such as Parson's puzzles [8,29]).

\section{Designing the Assessment}

Guided by ECD as a principled methodology for designing the assessment, our design process involved the following-

- Analyzing the domain of introductory programming using emergent K-12 CS standards and frameworks [5, 19] and research on middle school introductory programming [13] to articulate target concepts to be measured that are common to most programming environments.

- Developing assessment arguments known as focal knowledge, skills, and abilities (FKSAs) (Table 1) targeting programming concept-related abilities for which assessment items would elicit evidence [26]. Most FKSAs targeted comprehension and application levels of Bloom's Taxonomy [36], with a few targeting higher analysis and synthesis levels. These FKSAs represent "design patterns" for designing various forms of assessment (e.g. involving various programming languages) that target these set of conceptual programming knowledge and skills [27]. The FKSAs were also reviewed by experts.

- Designing items based on these FKSAs and iteratively refining them based on "cognitive interviews" [38] with 6 students, and two pilots in middle school classrooms with $\sim 200$ students, teacher feedback from 4 teachers (described in [16]), and review by an English Language Learning expert for accessible language. (See Table 3 for examples of refinement).

Table 1. Each FKSA below begins with "Ability to" -

\section{FKSAs derived from ECD \& Learning Goals}

1. Describe the execution that is performed by a (specific) given sequence of instructions (not including loops)

2. Describe what a given loop is doing

3. Describe the sequence that is executed in a given program when the program contains things inside and outside of the loop.

4. Show that a loop involves a repeating pattern, that will terminate under a specified condition or after a certain number of repetitions 5. Identify the repeating pattern within a loop

6. Describe the structural components of a pattern

7. Identify a pattern from a real-world phenomenon

8. Describe how a conditional pathway would operate or create a conditional pathway

9. Create variables, assign values and update variables

10. Describe how a variable changes values in a loop

11. Use a variable within a loop

12. Identify bugs related to overwriting values of variables (i.e. understanding that a variable can only hold one variable at a time)

13. Determine what variables are required in a program to achieve the goals of the computational solution.

14. Evaluate a Boolean expression

15. Use Boolean operators (And, Or, Not) in a program

16. Create a Boolean expression for a given condition

17. Identify sub-parts of a computational solution

18. Create a Boolean expression to control a loop

19. Identify a constant vs. a variable in a program

20. Decide on an appropriate initial value for a variable

21. Create an expression using existing variables

22. Define an abstraction to represent a general solution

Table 2. Nine Items, Sub-parts \& Concepts/FKSA covered

\begin{tabular}{|c|c|c|c|c|}
\hline Item & FKSA & Parts & Concepts & Points \\
\hline \multirow[t]{3}{*}{1} & \multirow[t]{3}{*}{$1,8,13$} & $\mathrm{a}$ & Boolean Exp.+Conditional & 1 \\
\hline & & $\mathrm{b}$ & Boolean Exp.+Conditional & 2 \\
\hline & & $\mathrm{c}$ & Boolean Exp.+Conditional & 2 \\
\hline \multirow[t]{2}{*}{2} & \multirow[t]{2}{*}{$1,8,12$} & $\mathrm{a}$ & Conditional+Relational Exp. & 3 \\
\hline & & $\mathrm{b}$ & Conditional + Variables & 2 \\
\hline \multirow[t]{3}{*}{3} & \multirow[t]{3}{*}{$2,3,9,10$} & $\mathrm{a}$ & Variables + Arith. Exp + Loops & 2 \\
\hline & & $\mathrm{b}$ & Variables + Arith Exp + Loops & 2 \\
\hline & & $\mathrm{c}$ & Variables + Loops & 1 \\
\hline \multirow[t]{7}{*}{4} & \multirow{7}{*}{\begin{tabular}{|l}
$2,3,4,8$, \\
$10, \quad 11$, \\
$14, \quad 15$, \\
$16,17,18$, \\
21,23
\end{tabular}} & a & Abstraction (Pattern Gen.) & 1 \\
\hline & & $\mathrm{b}$ & Abstraction (Pattern Gen.) & 1 \\
\hline & & $\mathrm{c}$ & Abstraction (Pattern Gen.) & 1 \\
\hline & & $\mathrm{d}$ & Variables + Arithmetic Exp. & 1 \\
\hline & & $\mathrm{e}$ & Variables + Boolean Exp + Loops & 1 \\
\hline & & $\mathrm{f}$ & Variables+ Arithmetic Exp + Loops & 2 \\
\hline & & $\mathrm{g}$ & Variable + Boolean Expression & 2 \\
\hline 5 & 14 & & Boolean Expression & 1 \\
\hline 6 & 14 & & Boolean Expression & 2 \\
\hline \multirow[t]{6}{*}{7} & \multirow{6}{*}{ 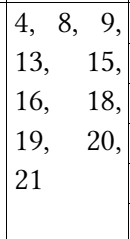 } & $\mathrm{a}$ & Variables $(\mathrm{V})$ & 5 \\
\hline & & $\mathrm{b}$ & Variables $(\mathrm{V})$ & 3 \\
\hline & & $\mathrm{c}$ & Variable + Arithmetic Expression & 2 \\
\hline & & $\mathrm{d}$ & Variable + Arithmetic Expression & 2 \\
\hline & & $\mathrm{e}$ & Variable + Boolean Expression & 2 \\
\hline & & $\mathrm{f}$ & Variables + Arithmetic Exp + Loops & 2 \\
\hline \multirow[t]{5}{*}{8} & \multirow{5}{*}{$\begin{array}{l}4,5,6,7 \\
11,22\end{array}$} & $\mathrm{a}$ & Pattern Recognition & 2 \\
\hline & & $\mathrm{b}$ & Abstraction (Pattern Gen.) & 2 \\
\hline & & $\mathrm{c}$ & Loops & 1 \\
\hline & & $\mathrm{d}$ & Loops & 4 \\
\hline & & $\mathrm{e}$ & Variables + Loops & 4 \\
\hline 9 & $2,3,4,5$ & & Loops & 4 \\
\hline
\end{tabular}


Table 3. Examples of items before and after refinement based on pilot studies of the assessment (a) Item \#3 and (b) Items \#5 \& \#6

(Before Revision) Item \#3: (a) Write down, in order, what will appear on the screen in the fox's speech box, after the green flag is clicked

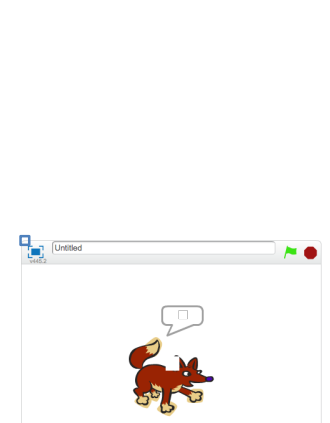

(b) Does the value of Number change in the loop? $\square$ Yes $\square$ No - If Yes, explain how it changes. [Text box for open response]

(c) Does the value of NumberofTimes change in the loop? $\square$ Yes No

If Yes, explain how it changes. [Text box for open response]

After Piloting and Refinement Item\#3 (a). After the green flag is clicked, what will the fox say?
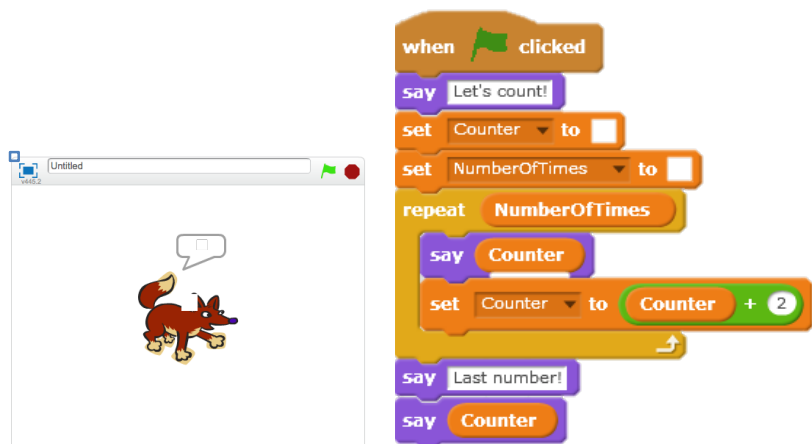

\begin{tabular}{|c|c|c|c|}
\hline \multirow{6}{*}{$\square \mathrm{A}$} & & \multirow{6}{*}{$\square \mathrm{B}}$. & Let's count! \\
\hline & Let's count! & & $\begin{array}{l}2 \\
4\end{array}$ \\
\hline & Counter & & 6 \\
\hline & Last number! & & 8 \\
\hline & & & Last number! \\
\hline & & & 8 \\
\hline \multirow{8}{*}{$\square \mathrm{C}}$. & Let's count! & \multirow{8}{*}{$\square \mathrm{D}}$. & Let's count! \\
\hline & 0 & & Counter \\
\hline & 2 & & Counter \\
\hline & 4 & & Counter \\
\hline & 6 & & Counter \\
\hline & 8 & & Counter \\
\hline & Last number! & & Last Number! \\
\hline & 10 & & Counter \\
\hline
\end{tabular}

3(b). In the program, does the value of Counter change in the loop? $\square$ Yes $\quad \square$ No

If Yes, explain how it changes. [Text box for open response]

3(c). In the program, does the value of NumberofTimes change in the loop? $\square$ Yes $\square$ No

If Yes, explain how it changes. [Text box for open response]
(Before Revision) Item \#5:(a) Select all pictures that match the Boolean condition where something has "legs OR wings."
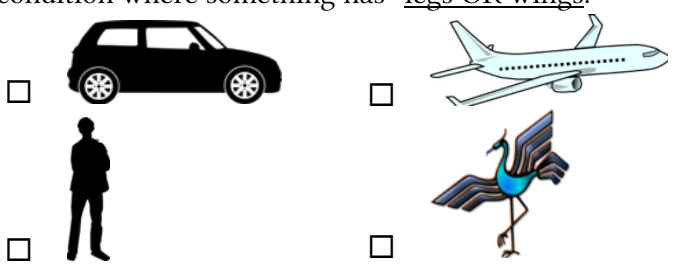

Item \#5:(b) Select all pictures that match the Boolean condition where something has "legs AND wings."
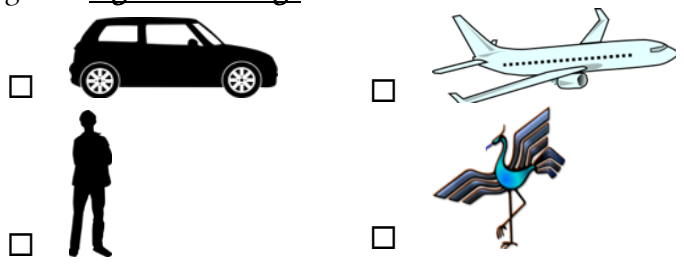

Item \#6: In the table below, check all of the words that satisfy each condition.

\begin{tabular}{|ll|llll|}
\hline \multicolumn{1}{|c|}{ Logical Expression } & \multicolumn{4}{|c|}{ Words } \\
\hline$\bullet$ & (Starts with a D) & $\square$ & DANCE & $\square$ & SOCCER \\
AND (ends with & $\square$ & DELICIOUS & $\square$ & SHARE \\
an E) & & & & \\
\hline$\bullet$ & (Starts with a D) & $\square$ & DANCE & $\square$ & SOCCER \\
& $\begin{array}{l}\text { AND does NOT } \\
\text { (end with an E) }\end{array}$ & $\square$ & DELICIOUS & $\square$ & SHARE \\
\hline$\bullet$ & (Starts with a D) & $\square$ & DANCE & $\square$ & SOCCER \\
OR (ends with an & $\square$ & DELICIOUS & $\square$ & SHARE \\
E) & & & & \\
\hline$\bullet$ & (Starts with a D) & $\square$ & DANCE & $\square$ & SOCCER \\
OR does NOT & $\square$ & DELICIOUS & $\square$ & SHARE \\
(end with an E) & & & & \\
\hline
\end{tabular}

\section{After Piloting and Refinement}

(Feedback: Item\#5- Students interpret images in ways we don't! Item\#6-Adults in the lab also got some wrong - they're confusing!)

Item \#5. Kathy takes an umbrella to school if it is raining.

She also takes an umbrella if it is cloudy.

She does not take an umbrella for any other weather.

Which Boolean expression shows this?

\section{$\square \quad$ Take umbrella IF (raining OR cloudy)}

Take umbrella IF (raining AND cloudy)

Item \#6: When the car is running it beeps a warning if your seatbelt is not fastened.

Which Boolean expression shows this?

$\square$ Warning beep IF ((Car running) OR (NOT Seatbelt fastened))

$\square$ Warning beep IF ((Car running) AND (NOT Seatbelt fastened))

$\square$ Warning beep IF ((Car running) OR (Seatbelt fastened))

$\square$ Warning beep IF ((Car running) AND (Seatbelt fastened)) 
Table 4. New items (\#7 \& \#8) added after piloting to address coverage of FKSAs and deeper conceptual understanding

Item \#7: You are programming a maze game. The screen shows a cat, maze walls, and gold coins. You make a cat move around the screen trying to find gold coins. The maze walls and coins stay in the same location every time you play the game.

- You start with a score of 0 .

- You have 5 lives at the start.

- If the cat touches a gold coin-

$$
\begin{aligned}
& \circ \quad \text { You gain a life, and } \\
& \circ \quad \text { your score increases by } 100 \text {. }
\end{aligned}
$$

- If the cat touches a wall-

$$
\begin{aligned}
& \text { you lose a life, and } \\
& \circ \quad \text { your score decreases by } 100 .
\end{aligned}
$$

The game ends when you reach a score of 500 or no lives are left. If your score is 500 when the game ends, you win. If your score is less than 500 when the game ends, you lose.

a. For each of the following, does it change as you play the game?

\begin{tabular}{|l|llll|}
\hline Score & $\square$ Changes & $\square$ & Does not change \\
\hline Lives & $\square$ Changes & $\square$ & Does not change \\
\hline Wall & $\square$ & Changes & $\square$ & Does not change \\
\hline Coins & $\square$ & Changes & $\square$ & Does not change \\
\hline Cat's Position & $\square$ & Changes & $\square$ & Does not change \\
\hline
\end{tabular}

b. Describe 1 variable that is needed to program this game.

- What would you name the variable?

- Describe the purpose of the variable.

- What is the starting value of the variable?

\begin{tabular}{|l|l|l|}
\hline $\begin{array}{l}\text { Variable } \\
\text { Name }\end{array}$ & $\begin{array}{l}\text { Describe how this variable is } \\
\text { used in the program (what is } \\
\text { the purpose of this variable) }\end{array}$ & $\begin{array}{l}\text { Starting value } \\
\text { of the } \\
\text { variable }\end{array}$ \\
\hline & & \\
\hline
\end{tabular}

c. What happens when the cat touches a gold coin?

- $\quad$ Use the IF block below (and variables 'Score' and 'Lives')

- Write the expressions one below the other to show how the value of the variables in the game changes.

\section{if touching gold coin $v$ ? then}

d. What happens when the cat runs into a Wall?

- Use the IF block below (and variables 'Score' and 'Lives')

- Write the expressions one below the other to show how the value of the variables in the game changes.

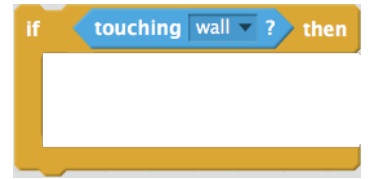

e. When does the game end? Use the following Repeat Until loop to write an expression to decide when the game ends.

\section{repeat until}

f. Write an "If" statement to decide if the player has won or lost. (Use variables)
Item \#8: A pattern is shown below.

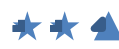

Step 1

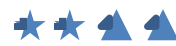

Step 2

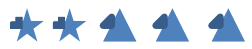

Step 3 a. Draw the next step (Step 4) in the pattern [Open-response]

b. Describe in words what the pattern would look like for Step 600 [Open response text box]

c. If you were write a program to produce Step 600 of this pattern, check mark which ONE of the following Scratch blocks that you would need:
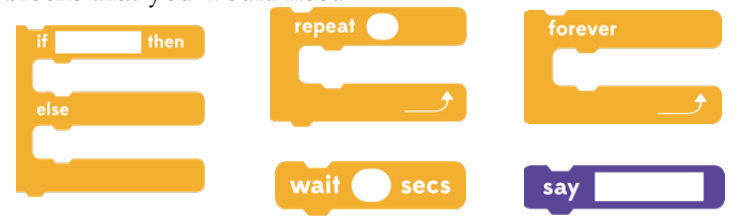

d. The following program draws Step 2 of the pattern:
Draw a star
Move to the right
Draw a star
Move to the right
Draw a triangle
Move to the right
Draw a triangle

Now write a program to draw Step 600 of the pattern. Use the Scratch block you picked in part c. You may use the Move and Draw commands as shown above. [Open-response text box]

e. Now, write a "pattern generator" program to draw the pattern for ANY Step number a user inputs. You may use the Move and Draw commands as shown above, along with Scratch commands.

The first part of the program looks like this-

\section{when clicked \\ ask What step of the pattern do you want to draw? and wait \\ set $\overline{\text { StepNumber } \boldsymbol{V}}$ to answer}

In the code snippet above, StepNumber is a variable whose value is set to whatever a user inputs (in the Ask command).

Continue the program below. Use StepNumber in your program instead of a value of a particular step. --

ask $\{$ What step of the pattern do you want to draw?\} and wait

set StepNumber to answer 


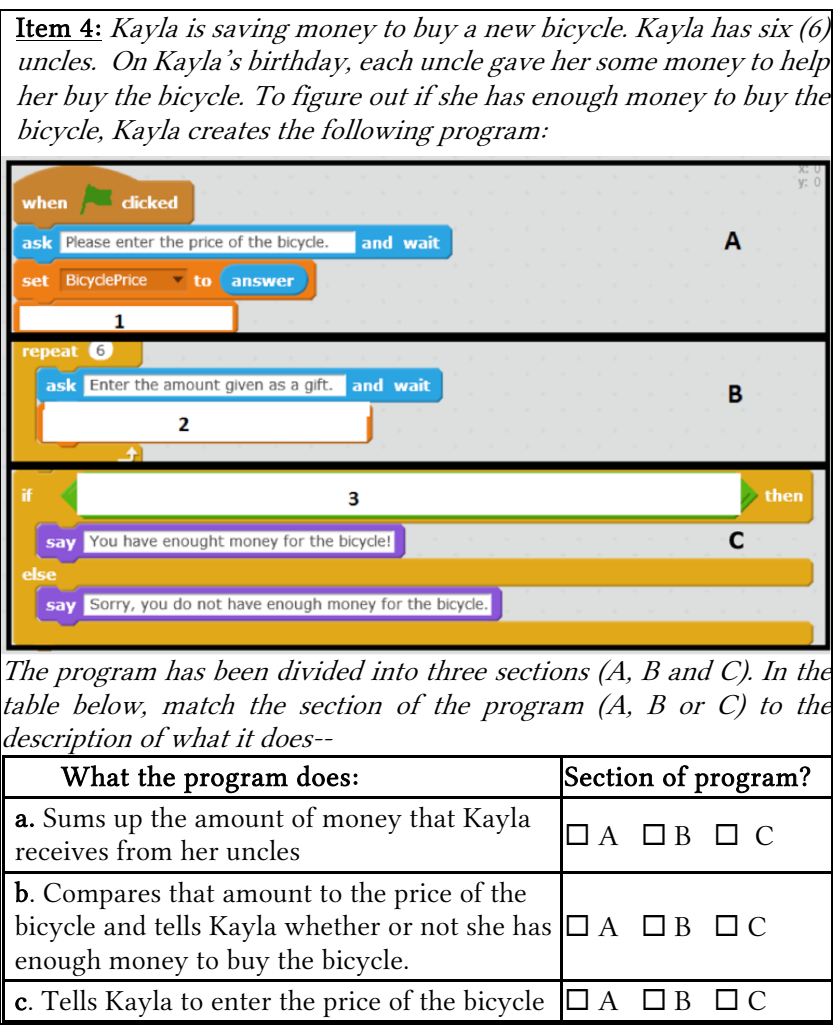

Figure 1. Item\#4 adapted to add identification of problem sub-parts

Finally, a paper-based assessment (also administerable online) to be completed over the course of a 45-50-minute class period was finalized (free for authorized educators at edfinity.com). It contains 9 multiple-choice and open-response items (with 29 individually scored sub-items). Table 2 reflects coverage by FKSA and concepts as well as assigned scores by sub-item. Some items (e.g.., \#2 and \#4) were adapted from items in the Israel national exam for middle school [42] and some from prior research in middle school CS [13]. Fig. 1 shows item \#4 adapted from [42] to add questions related to identifying sub-parts of a program (to address FKSA 17).

\section{Use of Assessment in Classroom}

We used the assessment as a pre-post measure for our introductory programming CS intervention involving 74 students in three classrooms (6th, 7th, and 8th grade) in an urban school district in Western US. These 3 classrooms reflected their schools' diversity in ethnicity, socio-economic status, and academic preparation (as measured by English and math scores on state-wide tests). In general, Grade 7 students belonged to a high socio-economic group and a high-achieving school with majority students at or above grade level in math and English, whereas both grades 6 and 8 largely comprised students identified as low socio-economic status, with high percentages at below-grade level in math and English state tests (see Table 5). All three classrooms were taught the same Scratch-based curriculum (described in [19]) that included activities designed to provide learners conceptual engagement with the foundational concepts (conditionals, loops, variables, expressions Boolean operators, and abstraction (by creating new variables using expressions and existing variables). The pre-post assessments were scored based on a rubric (e.g., see Fig 2. for item \#9 scoring rubric).
Table 5. Student and school sample characteristics

\begin{tabular}{|c|c|c|c|}
\hline & Grade 6 & Grade 7 & Grade 8 \\
\hline Male & 17 & 15 & 11 \\
\hline Female & 9 & 16 & 3 \\
\hline \multicolumn{4}{|c|}{ School characteristics (from district website) } \\
\hline Low SES & $85 \%$ & $40 \%$ & $87 \%$ \\
\hline Math Proficiency & $55 \%$ & $79 \%$ & $34 \%$ \\
\hline English Proficiency & $54 \%$ & $80 \%$ & $41 \%$ \\
\hline Learning Disabilities & $12.8 \%$ & $3.5 \%$ & $15 \%$ \\
\hline
\end{tabular}

\begin{tabular}{|c|c|c|}
\hline \multicolumn{3}{|c|}{$\begin{array}{l}\text { repeat } 3 \\
\text { say Hello! } \\
\text { say Goodbye! } \\
\text { stay Finished! } \\
\end{array}$} \\
\hline \multirow[t]{2}{*}{$\begin{array}{l}4 \text { points } \\
\text { Let's Start! } \\
\text { Hello! } \\
\text { Goodbye! } \\
\text { Hello! } \\
\text { Goodbye! } \\
\text { Hello! } \\
\text { Goodbye! } \\
\text { Finished! }\end{array}$} & \multirow[t]{2}{*}{$\begin{array}{l}3 \text { points } \\
\text { Hello! } \\
\text { Goodbye! } \\
\text { Hello! } \\
\text { Goodbye! } \\
\text { Hello! } \\
\text { Goodbye! } \\
\text { (missing Let's Start! or } \\
\text { Finished! or both) }\end{array}$} & $\begin{array}{l}1 \text { point } \\
\text { Correct Let's Start! and } \\
\text { Finished! but incorrect loop } \\
\text { part (no repetition, or } \\
\text { grouped loop) }\end{array}$ \\
\hline & & O for all other responses \\
\hline
\end{tabular}

Figure 2. Rubric showing scoring for item \#9

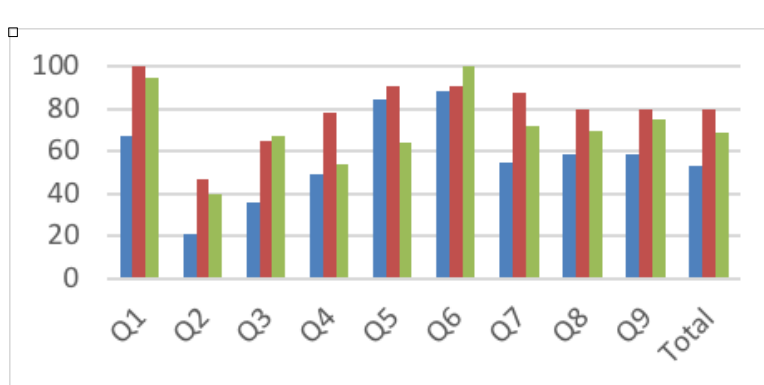

arade 6 Grade 7 Grade 8

Figure 3. Average scores on each item by grade

\subsection{Results}

Average post-scores were $53 \%, 80 \%, 69 \%$ for Grades 6, 7, \& 8, each of which were significantly higher than average pretest scores (39\%,66\% \& 56\% respectively). Grade level was positively correlated with score for grades $6 \& 7$. Grade 8 performed worse than Grade 7 , however overall posttest scores were significantly and positively correlated to students' prior English and Math scores on state assessments. The assessment appeared to be difficult for Grade 6 . Item-wise analysis by concepts and grade ((Fig. 3, 4) revealed that grade 6 struggled more with combinations of concepts than did grade 7. Item \#6 was the easiest for all. Item \#2 was difficult for all students (due to poor wording) and needed revision. However, it is important to remember that several factors contribute to student performance in addition to the assessment itself, including the curriculum, teacher CS experience and expertise, and students' 
background and academic preparation. Our grade 6 student sample comprised low-performing students compared to grade 7 .

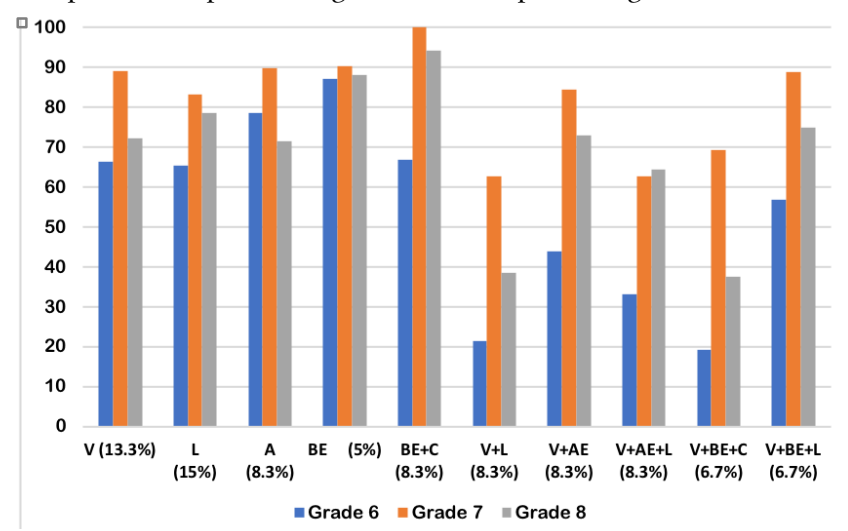

Figure 4. Average concepts-wise scores by grade

\subsection{Validity, Reliability, Discrimination and Difficulty Analyses of Assessment \& Items}

The domain analysis and modeling phases of the ECD design process help establish a baseline level of test validity [25] as do student responses in cognitive interviews. Current conceptions of test validity also see reliability as integral to validity [1]. Factor analyses on our classroom use data (from all three grades) revealed that the assessment was measuring one overall factor suggesting high internal consistency among the items. The assessment items reflected a high level of reliability at $82 \%$. The Discrimination Index (DI) of an item (or assessment) reflects how well an item (or assessment) differentiates between high and low scorers. Item discrimination analysis revealed that items targeting combinations of programming concepts rather than individual concepts (Items \#4, \#7, \#8, \#9) had higher discriminatory power. The Discrimination and Difficulty Index (average score across all grades) and of each item are shown in Table 6. It is worth noting that Item\#9 (Fig 2) has the highest DI. It demonstrates the value of a relatively easy and simple item in revealing conceptual understanding or the lack thereof, of a key concept such as loops (as in a concept inventory).

Table 6. Item-wise difficulty and discrimination indices

\begin{tabular}{|l|c|c|c|c|c|c|c|c|c|}
\hline & $\# 1$ & $\# 2$ & $\# 3$ & $\# 4$ & $\# 5$ & $\# 6$ & $\# 7$ & $\# 8$ & $\# 9$ \\
\hline Difficulty (Avg. score) & .86 & .35 & .54 & .63 & .84 & .90 & .71 & .69 & .71 \\
\hline Discrimination & .37 & .62 & .46 & .61 & .35 & .20 & .51 & .50 & .68 \\
\hline
\end{tabular}

\section{Discussions, Reflections \& Lessons Learned}

Besides the creation of a valuable tool, there are many takeaways and lessons learned from this process and experience report.

Based on validity, reliability, difficulty and discrimination analyses of the items and instrument, the assessment represents a solid early attempt as a measure of introductory programming concepts. The significant increase from pre-to-post intervention shows that the assessment is sensitive to instruction (another key criterion for test validity). Assessment literature views DIs between 0.25 and 0.39 as good and those above 0.40 as excellent [4,22]. This assessment is of medium difficulty. Given the findings in the context of the three classrooms that used the assessment, and the lower performance of Grades $6 \& 8$ (which not only had students with poor academic preparation but also uneven sample sizes), the assessment should be used in other settings to understand its quality more broadly. The difficulty (especially for $6^{\text {th }}$ graders) of certain items is consistent with levels of Bloom's taxonomy. While Items \#1, \#5, and \#6 dealt with single concepts and comprehension/application, Items \#4, \#7, \#8, \& \#9 involved combinations of concepts and captured analysis and synthesis of programming concepts. Use of this assessment with grade 6 should be done keeping these data in mind.

This assessment contains a mix of multiple-choice as well as openresponse item types involving Scratch (one of the more popular environments for introductory programming in middle grades). Our rubrics provide detailed guidelines for partial grading of openresponse items. Although giving partial credit in open-ended items makes scoring more complex and time-consuming, an assessment that includes some open-response items that require students to write pseudo-code, construct expressions, or provide explanations makes for a richer assessment and helps provide better evidence of student understanding than multiple-choice items alone.

It is important to note that several factors contribute to student performance in an assessment, including (among others) the CS curriculum, teacher CS experience and expertise, and students' background and academic preparation [14]. It is therefore crucial that such an assessment not be the only measure for "grading" a student at the end of the course, but one of many varied forms of assessment (such as final projects among other tasks, and measures of attitudes and interest) that can provide a holistic measure of student learning and engagement [15]. This is important since desired outcomes for current CS initiatives include students' conceptual growth and also affective measures such as identity development, motivation, and engagement [19].

The reasons for using ECD included the inbuilt validity \& in-process alignment, the creation of generalizable design patterns that can be used for creating other assessments from the same FKSAs, and the availability of a prior example of its use for the design of a high school CS assessment [32]. Note that we did not consider the SOLO taxonomy used in some CS assessment research [21] as it defines levels in terms of responses a student may give to a task which was not aligned with this effort. CS researchers have also found Bloom's Taxonomy to be difficult to apply consistently to assessment tasks in introductory programming courses [9].

In summary, this paper shares a robust summative assessment for middle school CS for middle school CS and describes the experience of creating such a tool focused primarily on introductory programming concepts. The multi-layered design process guided by ECD, a principled assessment design approach, ensures alignment between items and target focal knowledge, skills, \& abilities. We discuss key features of the assessment as well as almost all the items and share examples of scoring rubrics. This work and paper make a significant contribution to the field, benefiting students, teachers and administrators working in the uncharted-yet-rapidlyexpanding realm of teaching CS as new subject in K-12 classrooms. The design process ensures broad use for this instrument, its accompanying rubrics, and the assessment design patterns developed, which can also guide adaptation of items to other programming languages. Our next steps involve refining Item\#2 and testing more broadly with larger and diverse student samples. 


\section{- ACKNOWLEDGEMENTS}

We thank the National Science Foundation (DRL\#1543062) for grant funding. Thanks to researchers at SRI International and the partner school district for participating and partnering in this work.

\section{- REFERENCES}

[1] AERA, APA, \& NCME (American Educational Research Association, American Psychological Association, \& National Council on Measurement in Education). 2014. Standards for educational and psychological testing. Washington, DC: AERA

[2] Bau, D., Gray, J., Kelleher, C., Sheldon, J., \& Turbak, F. 2017. Learnable programming: blocks and beyond. Communications of the ACM, 60(6), 72-80.

[3] Bienkowski, M., Snow, E., Rutstein, D. and Grover, S., 2015. Assessment design patterns for computational thinking practices in secondary computer science: A first look. SRI International.

[4] Brennan, R. L. 1972. A generalized upper-lower item discrimination index. Educational and Psychological Measurement, 32(2), 289-303.

[5] Computer Science Teachers Association. 2017. CSTA K-12 Computer Science Standards, Revised 2017. Retrieved from http://www.csteachers.org/standards.

[6] Cooper, S., Grover, S., Guzdial, M., \& Simon, B. 2014. A future for computing education research. Communications of the ACM, 57(11), 34-36.

[7] DeLyser, L. \& Song, J. (2017) Identifying the Needs of the CS Ed Community in the US. In Proceedings of the thirteenth annual ACM International Computing Education Research (ICER) conference, Tacoma, WA. ACM.

[8] Denny, P., Luxton-Reilly, A. and Simon, B., (2008) Evaluating a new exam question: Parsons problems. In Proceedings of the fourth annual ACM International Computing Education Research (ICER) conference, 113-124 .

[9] Gluga, R., Kay, J., Lister, R., Kleitman, S., \& Lever, T. (2012, February). Overconfidence and confusion in using Bloom for programming fundamentals assessment. In Proceedings of the 43rd ACM technical symposium on Computer Science Education (pp. 147-152). ACM.

[10] González, M. R. (2015). Computational thinking test: Design guidelines and content validation. In Proceedings of EDULEARN15 conference (pp. 24362444).

[11] Goode, J., Chapman, G. \& Margolis, J., 2012. Beyond curriculum: the exploring computer science program. ACM Inroads, 3(2), pp.47-53.

[12] Grover, S. \& Pea. R. 2013. Computational thinking in K-12: A review of the state of the field. Educational Researcher, 42(1), 38-43.

[13] Grover, S. 2014. Foundations for advancing computational thinking: balanced designs for deeper learning in an online computer science course for middle school students. Stanford University.

[14] Grover, S., Pea, R. and Cooper, S., 2016, February. Factors influencing computer science learning in middle school. In Proceedings of the 47th ACM technical symposium on computing science education (pp. 552-557). ACM.

[15] Grover, S. 2017. Assessing Algorithmic and Computational Thinking in K-12: Lessons from a Middle School Classroom. In Emerging Research, Practice, and Policy on Computational Thinking (p. 269-288). Springer International.

[16] Grover, S. \& Basu, S. (2017). Measuring Student Learning in Introductory Block-Based Programming: Examining Misconceptions of Loops, Variables, and Boolean Logic. In Proceedings of the 48th ACM Technical Symposium on Computer Science Education (SIGCSE '17). Seattle, WA: ACM.

[17] Grover, S., Basu, S., Bienkowski, M., Eagle, M., Diana, N., \& Stamper, J. 2017. A Framework for Using Hypothesis-Driven Approaches to Support Data-Driven Learning Analytics in Measuring Computational Thinking in Block-Based Programming Environments. ACM Transactions on Computing Education (TOCE), 17(3), 14.

[18] Grover, S., Jackiw, N. \& Lundh, P. 2019. Concepts Before Coding: NonProgramming Interactives to Advance Learning of Introductory Programming Concepts in Middle School. Computer Science Education. DOI: $\underline{10.1080 / 08993408.2019 .1568955}$

[19] K-12 CS Framework Committee. 2016. K-12 Computer Science Framework. Retrieved from http://www.k12cs.org.

[20] Lister, R., (2005) One small step toward a culture of peer review and multiinstitutional sharing of educational resources: a multiple-choice exam for first semester programming students. Seventh Australasian Computing Education Conference (ACE2005), 155-164

[21] Lister, R., Simon, B., Thompson, E., Whalley, J. L., \& Prasad, C. (2006). Not seeing the forest for the trees: novice programmers and the SOLO taxonomy. ACM SIGCSE Bulletin, 38(3), 118-122.

[22] Matlock-Hetzel, S. 1997). Basic Concepts in Item and Test Analysis. Paper presented at the Annual Meeting of the Southwest Educational Research Association (Austin,TX, January 23-25, 1997).

[23] Meerbaum-Salant, O., Armoni, M., \& Ben-Ari, M. 2010. Learning compute science concepts with Scratch. In Proceedings of the Sixth International Workshop on Computing Education Research (ICER '10). ACM. 69-76.

[24] Messick, S. (1989). Validity. In R. Linn (Ed.), Educational measurement (3 ${ }^{\text {rd }}$ ed.) pp13-103.New York: Macmillian. 13-103.

[25] Mislevy, R. J., Steinberg, L. S., \& Almond, R. G. (2003). Focus article: On the structure of educational assessments. Measurement: Interdisciplinary research and perspectives, 1(1), 3-62

[26] Mislevy, R. J., \& Riconscente, M. M. (2005). Evidence-centered assessment design: Layers, structures, and terminology. Menlo Park, CA: SRI International, 26.

[27] Mislevy, R. J., \& Haertel, G. D. (2006). Implications of evidence-centered design for educational testing. Educational Measurement: Issues and Practice, 25(4), 620 .

[28] Moskal, B., Lurie, D., \& Cooper, S. (2004). Evaluating the effectiveness of a new instructional approach. ACM SIGCSE Bulletin, 36(1), 75-79.

[29] Parsons, D. and Haden, P., 2006, January. Parson's programming puzzles: a fun and effective learning tool for first programming courses. In Proceedings of the 8th Australasian Conference on Computing Education-Volume 52 (pp. 157163). Australian Computer Society, Inc..

[30] Project Quantum. https://diagnosticquestions.com/Quantum

[31] Roberts, T., (2006) The use of multiple choice tests for formative and summative assessment. Eighth Australasian Computing Education Conference (ACE2006), 175-180

[32] Snow, E., Rutstein, D., Bienkowski, M., \& Xu, Y. (2017, August). Principled Assessment of Student Learning in High School Computer Science. In Proceedings of the 2017 ACM Conference on International Computing Education Research (pp. 209-216). ACM.

[33] Starr, C.W., Manaris, B., \& Stalvey, R.H. 2008. Bloom's taxonomy revisited: specifying assessable learning objectives in computer science. ACM SIGCSE Bulletin, 40(1), 261-265

[34] Taylor, C., Zingaro, D., Porter, L., Webb, K. C., Lee, C. B., \& Clancy, M. (2014). Computer science concept inventories: past and future. Computer Science Education, 24(4), 253-276

[35] Tew, A. E. and Guzdial, M. Developing a validated assessment of fundamentalCS1 concepts. InProceedings of the 41st ACM Technical Symposium on ComputerScience Education, pages 97-101, 2010

[36] Thompson, E., Luxton-Reilly, A., Whalley, J.L., Hu, M. and Robbins, P. 2008. Bloom's taxonomy for CS assessment. In Proceedings of the tenth conference on Australasian computing education, 78, 155-161

[37] Werner, L., Denner, J., Campe, S., and Kawamoto, D. 2012. The Fairy performance assessment: Measuring computational thinking in middle school. Paper presented at the Proceedings of the 43rd ACM Technical Symposium on Computer Science Education, New York, NY.

[38] Willis, G. B. 2004. Cognitive interviewing: A tool for improving questionnaire design. Sage Publications.

[39] Wiebe, E., London, J., Aksit, O., Mott, B. W., Boyer, K. E., \& Lester, J. C. (2019, February). Development of a Lean Computational Thinking Abilities Assessment for Middle Grades Students. In Proceedings of the 50th ACM Technical Symposium on Computer Science Education (pp. 456-461). ACM.

[40] Woodford, K. \& Bancroft, P., (2005) Multiple choice questions not considered harmful. Seventh Australasian Computing Education Conference (ACE2005), 109-115

[41] Yadav, A., Burkhart, D., Moix, D., Snow, E., Bandaru, P., \& Clayborn, L. (2015) Sowing the Seeds: A Landscape Study on Assessment in Secondary Computer Science Education.

[42] Zur-Bargury, I., Pârv, B., \& Lanzberg, D. (2013, July). A nationwide exam as a tool for improving a new curriculum. In Proceedings of the 18th ACM conference on Innovation and technology in computer science education (ITiCSE). (pp. 267-272). ACM. 